\title{
Evidence in support of word unitization
}

\author{
WILLIAM P. O'HARA \\ University of Illinois at Urbana-Champaign, Champaign, Illinois 61820
}

\begin{abstract}
In each of five experiments, the subjects viewed tachistoscopically presented pairs of letters and made speeded comparison judgments on the basis of name identity. On most trials, a noise letter string (word or anagram) was placed directly between the target letters. The results indicated that correct "same" RTs were a function of noise item type and its relation to target letters. Anagrams increased RTs more than their counterpart words, except when the noise word was either unmeaningful or response incompatible with respect to the target letters (e.g., B Tea b). The interference effects were also found to be independent of sequence length. It was posited that the subjects were unable to completely ignore the irrelevant attributes of the displays and that under certain conditions, the subjects were able to identify the noise items in a holistic fashion. The data were interpreted in terms of a unitization hypothesis of word recognition, response competition, and a continuous-flow conception of information processing.
\end{abstract}

In a recent paper, O'Hara and Eriksen (1979) demonstrated the paradigmatic value of a characterclassification task with interference as a means of examining and supporting a unitization hypothesis of word recognition. Their subjects viewed tachistoscopically presented pairs of letters which were physically identical, name identical, or different, and made speeded comparison judgments on the basis of name identity. On some of the trials, noise trigrams composing either nonwords or familiar words appeared between the target letters (e.g., B ODG b or B DOG b). As expected, correct "same" responses were faster for PI than for NI letter pairs. Surprisingly, however, correct "same" reaction times (RTs) were also a function of noise type. Anagrams increased RTs significantly more than their counterpart words. Word noise, on the other hand, failed to appreciably affect RTs compared to the no-noise condition.

Since the word and anagram items were composed of the same letters, O'Hara and Eriksen attributed the differential noise effects to the subjects' ability to perceptually unitize the word noise. They posited that a unitized word's featural or memorial representation would not interfere with the comparison task. The anagrams, however, were likely perceived as a group of free-floating letters and processed along with the target letters to the point of incipient response activation. At this juncture, response compe-

This article is based on a PhD dissertation submitted to the University of Illinois in October 1979. The research was supported by U.S. Public Health Service Research Grant MH-01206 to C. W. Eriksen. I would like to acknowledge the help of my doctoral committee members, Christopher D. Wickens, Gerald Salancik, Edward Shoben, Stephen Golding, and a special thanks to my committee chairman, Charles W. Eriksen, for his continuous encouragement and advice. Requests for reprints should be sent to William O'Hara at the Department of Psychology, University of Illinois, Champaign, Illinois 61820. tition (target-noise incompatibility) occurred, producing the observed RT impairment.

Whether reading a word involves recognizing its familiar visual configuration, as concluded by O'Hara and Eriksen, or, instead, a letter-by-letter analysis has been the subject of controversy for over a century. Early proponents of the word unitization theory of word recognition, such as Cattell, Erdman, Dodge, and Huey, contended that the perception of words was mediated to a greater extent by their total outline than by their constituent letters. Support for this notion has been provided by a number of relevant findings: (1) words with distinctive outlines are recognized at distances far too great for recognition of individual letters (Huey, 1908/1968), (2) short words can be verbalized as quickly as single letters (Cattell, 1886), (3) words that have similar outlines are often mistaken for one another (Havens \& Foote, 1963), (4) words can be identified more quickly than letters within words (Johnson, 1975), and (5) under certain conditions, recognition accuracy for single letters is better when they are embedded in a word than in a nonword or displayed alone (Reicher, 1969; Wheeler, 1970).

Opponents of the word unitization hypothesis often argue that since written English consists of tens of thousands of words, word-pattern recognition would be a phenomenally complicated task. On the other hand, English has only 26 letters that can be distinguished on the basis of as few as five features, making the letter or the literal feature the more likely unit of perception. As pointed out by Adams (Note 1), however, the units of perception need not be the same as the units of visual analysis. One unit might serve as the basis of analysis, while the other might be used for perception.

Another group of investigators (Estes, 1975; Henderson, 1975; McClelland, 1976) argue that the 
results supporting the whole-word theory of recognition can be predicted on the basis of a preliminary letter analysis model incorporating a parallel letter analysis which continuously feeds to a word identification stage. Accordingly, McClelland (1977) contends that global shape information is used to determine which letters would possibly fit in each letter position. This information is then fed to a word identification stage which finds a word consistent with the letter and positional information provided.

An important prediction made by the preliminary letter analysis model and other feature integration models of word recognition is that prior to word recognition, letter recognition occurs. The results of O'Hara and Eriksen (1979) failed to support such a notion. If letter recognition always preceded word recognition, then word noise should have produced interference effects similar to anagram noise. O'Hara and Eriksen found, however, little or no RT impairment due to word noise. They concluded, therefore, in agreement with others (Hayes-Roth, 1977; Johnson, 1977), that individual letters contained within unitized words need not be recognized prior to those words being recognized.

\section{EXPERIMENT 1}

The experiments reported here expanded the use of the interference classification task designed by O'Hara and Eriksen (1979) in order to provide additional evidence to support the word unitization hypothesis. Initially, this was accomplished by rerunning the original experiment but using a larger set of target letters and noise trigrams.

In order to investigate the level to which the wordnoise items were processed, each subject participated in a recognition task after the stimulus display session. Keren, O'Hara, and Skelton (1977), as well as Eriksen and Eriksen (1974), had previously reported data indicating that noise items were processed at least to the level of target items; O'Hara and Eriksen (1979) further stipulated that their word-noise items were recognized as familiar words. If so, these words should have been remembered by the subjects. The incidental learning task was designed to test this hypothesis.

\section{Method}

Subjects. Eight University of Illinois students served as paid volunteers. Each was right-handed and had either normal or corrected-to-normal vision.

Stimuli and Apparatus. Target stimuli consisted of black letters typed on white index cards using IBM Orator L/A 12 type. At the viewing distance of $84 \mathrm{~cm}$, these letters subtended .17 and $.29 \mathrm{deg}$ of visual angle in width and height, respectively. Full displays consisted of either two target letters alone (null condition) or two target letters and a letter trigram (word and anagram conditions). Instead of using capital letter trigrams as in the O'Hara and Eriksen study, only the initial letter of each trigram was capi- talized. The target letters always appeared at the extreme right and left of the visual display, separated by $1.19 \mathrm{deg}$ of visual angle. When included, the noise trigrams, subtending $.51 \mathrm{deg}$ of visual angle, always appeared directly between the two target letters and separated from each by $.34 \mathrm{deg}$ of visual angle. The width of the entire display was $1.53 \mathrm{deg}$ of visual angle.

The 10 letters used to develop letter pairs were chosen randomly from the alphabet, excluding the letters $I, Q, O$, and $Z$. The 20 physically identical (PI) letter pairs were paired replications of each of the 10 target letters in both uppercase and lowercase forms. The 20 name identical (NI) pairs were constructed by changing the case of one of the letters in each of the PI letter pairs; 10 of the NI pairs began and 10 ended in uppercase letter forms. "Different" letter pairs were composed of the same letters used for the "same" pairs, with the restrictions that 20 of the pairs be composed of the same case letters (uppercase or lowercase), 20 have mixed letter cases, and all the letters be used equally often.

The word trigrams used as noise elements were chosen randomly from a set of 80 three-letter words taken from a list provided by Kučera and Francis (1967); 20 of the words were used for "same" trials and 20 for "different" trials. The anagrams were produced by repositioning the second letter of each word to either the first or third letter position so as to produce a nonword. The target letters and noise trigrams are listed in Table 1.

Stimuli were displayed in a Scientific Prototype Model $800 \mathrm{~F}$ two-field tachistoscope equipped with ITT F6T5/CW fluorescent lamps. The luminance of the white background in both fields was set at $41 \mathrm{~cd} / \mathrm{m}^{2}$. RTs were recorded to the nearest millisecond on a Hunter Klockounter.

Procedure. Subjects were instructed to fixate on a small cross that appeared in the center of the visual field and to make sure the cross was in good focus before initiating a trial by pushing a button held in the left hand. Immediately thereafter, the fixation field was replaced by the stimulus display which remained on for $250 \mathrm{msec}$. After this period, the fixation field reappeared. The subjects were then instructed to make a lever response with the right hand, to the right (left) if the target stimuli were NI and to

Table 1

Target Letters and Noise Trigrams Used in Experiment 1

\begin{tabular}{|c|c|c|c|c|c|c|c|}
\hline & & & & \multicolumn{4}{|c|}{ "Different" } \\
\hline \multicolumn{4}{|c|}{ "Same" } & \multicolumn{2}{|c|}{ Case } & \multirow[b]{2}{*}{ Word } & \multirow[b]{2}{*}{$\begin{array}{l}\text { Ana- } \\
\text { gram }\end{array}$} \\
\hline PI & NI & Word & $\begin{array}{l}\text { Ana- } \\
\text { gram }\end{array}$ & Same & $\begin{array}{c}\text { Differ- } \\
\text { ent }\end{array}$ & & \\
\hline BB & $\mathrm{Bb}$ & Cry & Rcy & $\mathrm{BE}$ & $\mathrm{Bt}$ & Are & Aer \\
\hline DD & $\mathrm{Dd}$ & Hat & $\mathrm{Hta}$ & DT & Dr & Who & Owh \\
\hline $\mathrm{EE}$ & $\mathrm{Ee}$ & Sit & Sti & ER & $\mathrm{Em}$ & Any & Ayn \\
\hline FF & $\mathrm{Ff}$ & Lie & Ile & FM & $\mathrm{Fj}$ & God & Odg \\
\hline GG & $\mathrm{Gg}$ & Met & Mte & GJ & Gh & Put & $\mathrm{Upt}$ \\
\hline $\mathrm{HH}$ & $\mathrm{Hh}$ & Key & Ehk & JB & $\mathrm{Hg}$ & Act & Atc \\
\hline JJ & $\mathbf{J j}$ & Sea & Esa & JD & Jf & Air & Ari \\
\hline MM & $\mathrm{Mm}$ & Box & Bxo & MF & $\mathrm{Me}$ & Run & Rnu \\
\hline RR & $\mathrm{Rr}$ & Lot & Olt & RG & Rd & Top & Opt \\
\hline $\mathrm{TT}$ & $\mathrm{Tt}$ & Lay & Lya & TH & $\mathrm{Tb}$ & Son & Osn \\
\hline $\mathrm{bb}$ & bB & Low & Olw & bh & $\mathrm{bF}$ & Aid & Iad \\
\hline dd & $\mathrm{dD}$ & Yes & Yse & dg & dG & Sun & Snu \\
\hline ee & $\mathrm{eE}$ & Buy & Byo & ef & eG & Gun & Ugn \\
\hline ff & $\mathrm{fF}$ & Car & Acr & fd & fJ & Arm & $\mathrm{Amr}$ \\
\hline gg & gG & Law & Lwa & $\mathrm{gb}$ & $\mathrm{gM}$ & Bit & $\mathrm{Bti}$ \\
\hline hh & $\mathrm{hH}$ & End & Edn & jh & hR & Dog & Ogd \\
\hline ji & $\mathrm{j} J$ & War & Wra & $\mathrm{jm}$ & jT & Lit & $\mathrm{Lti}$ \\
\hline $\mathrm{mm}$ & $\mathrm{mM}$ & Now & Onw & $\mathrm{mr}$ & $\mathrm{mB}$ & Sat & Ast \\
\hline II & $\mathrm{rR}$ & You & Yuo & rt & ID & Hit & Iht \\
\hline $\mathrm{tt}$ & $\mathrm{tT}$ & For & Ofr & te & $\mathrm{tE}$ & Sin & Isn \\
\hline
\end{tabular}


the left (right) when the target letters had different names. The subjects were also told that on some trials words or anagrams would appear in the center of the display in addition to the target letters. The subjects were told that these trigrams had nothing to do with the task and should, therefore, be ignored.

The subjects were further instructed to respond as rapidly as possible but to attempt to maintain a low error rate. Trials on which errors did occur were not rerun. In order to provide performance feedback, the subject was informed of his or her speed and accuracy after each trial.

Each subject participated in only one experimental session and, prior to data collection, took part in a short practice session consisting of 15 no-noise and $\mathbf{3 0}$ noise trials. Practice displays were not reused during the experimental session.

During each experimental session, there were 80 no-noise trials divided equally among the PI and NI levels of the "same" target match condition, and the same and different case levels of the "different" target-match condition. Furthermore, each of the 20 words and corresponding anagrams chosen for the "same" condition was displayed with a PI and NI letter pair, and each of the 20 words and corresponding anagrams was paired with one of the same and one of the different case target pairs. Each of the above 12 target pairs or target-noise combinations was randomly mixed in blocks of 12 displays, resulting in a total of 240 experimental displays.

After the completion of the experimental tachistoscopic session, each subject's memory for the word-noise items was tested using a two-alternative forced-choice (2AFC) recognition task. The task consisted of examining $\mathbf{4 0}$ pairs of words, 20 for "same" and 20 for "different" word-noise items, and circling the word remembered as having been a noise item. In those cases where the subject was unsure, he was instructed to guess. Target foils were the remaining $\mathbf{4 0}$ words not used as noise items from the initial set of 80 words taken from Kučera and Francis (1967).

\section{Results and Discussion}

Correct "same" RTs averaged across subjects are illustrated in Figure 1 as a function of target and noise type. Also displayed are the data reported by O'Hara and Eriksen (1979). Except for an overall reduction of $\mathrm{RT}^{\mathbf{1}}$ subtracted from the previous data for illustrative purposes, the present results essentially replicated those reported by O'Hara and Eriksen.

A repeated-measures analysis of variance (Target Type by Noise Type) yielded significant main effects for target type $[F(1,7)=23.74, p<.01]$, noise type $[F(2,14)=62.85, p<.01]$, and a significant interaction of these two factors $[F(2,14)=4.04, p<.05]$. The target-type main effect reflects the commonly reported observation that subjects can more rapidly determine that two letters are NI when they are PI as well (Keren et al., 1977; O'Hara \& Eriksen, 1979; Posner \& Mitchell, 1967).

A result of major interest was the significant interaction of target type and noise type. When examined in detail, this interaction was found to be produced entirely by the effect of anagram noise impairing RTs for NI matches more than for PI matches. The repeated-measures analysis of variance comparing target type with anagram and word noise revealed significant main effects of target type $[F(1,7)=28.59$, $\mathrm{p}<.01]$ and noise type $[\mathrm{F}(1,7)=36.70, \mathrm{p}<.01]$, as well as for the interaction of these two factors $[F(1,7)=$

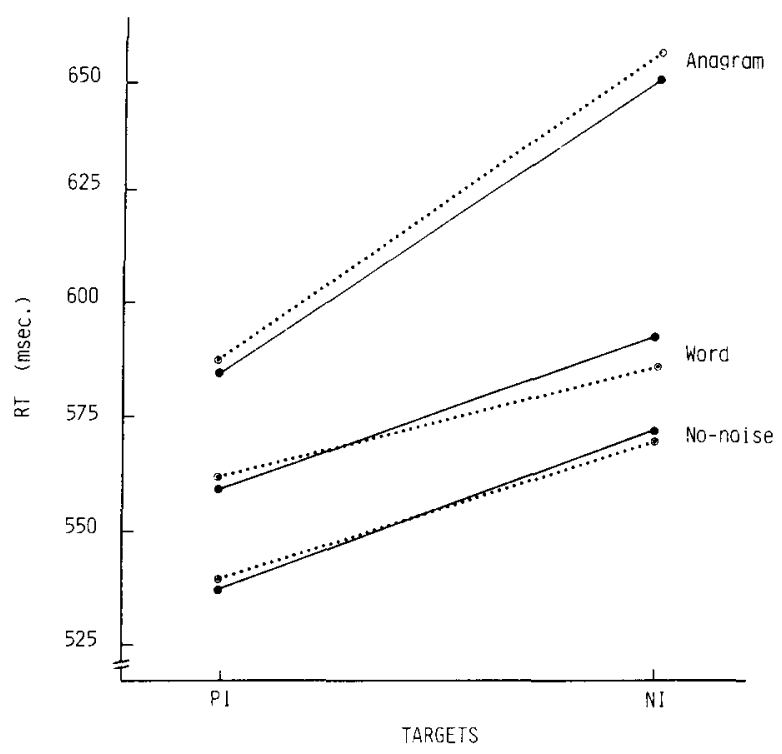

Figure 1. Mean RTs for correct "same" judgments as a function of target type (physically identical, PI; or name identical, NI) and noise type (no-noise, word, and anagram) for the present experiment (solid lines) compared to O'Hara and Eriksen's (1979) results (dotted lines). Ninety milliseconds were subtracted from the latter means for the purpose of illustration.

$8.66, p<.05]$. In contrast, the same analysis, but comparing target type with the word and no-noise conditions, revealed no such interaction $(p>.05)$, although both target and noise type effects were significant $[F(1,7)=10.62, p<.01$ and $F(1,7)=19.57$, $\mathrm{p}<.01$, respectively].

One might speculate that these results reflect the level at which noise items interfered with the processing of the target items. Since it has been hypothesized that the features used to recognize unitized words need have little or no overlap with those features utilized for letter recognition, and that the letter units need not be perceived prior to word recognition (Hayes-Roth, 1977; Johnson, 1977), little word-noise interference should have been found. The obtained slight, but noninteractive, word-noise effect possibly reflects the additional processing or time allocation required to process any added configural information (Kahneman, 1973; Regan, 1978). However, since anagrams could have only been perceived as a group of free-floating letters, they caused multiple response competition effects. When the targets were PI, the interference was at the feature level; when an NI match was required, targets and noise items were processed together (Keren et al., 1977) to the namerecognition level (Posner \& Mitchell, 1967), where maximum response competition occurred. Alternatively, it could be argued that the NI stimuli were responded to more slowly than the PI stimuli and, therefore, more time was allotted for noise interference to occur for these displays. 
Since error rates for "same" responses increased with RTs across conditions, speed-accuracy tradeoffs were excluded as the source of the observed effects. Collapsed across noise conditions, the error rate was $2.5 \%$ for PI matches and $6.5 \%$ for NI matches. For noise conditions collapsed across levels of target matches, the error rates were $3.8 \%, 4.4 \%$, and $5.3 \%$ for the no-noise, word-noise, and anagramnoise conditions, respectively.

As expected, the repeated-measures analysis of variance (Target Type by Noise Type) used to examine "different" RTs failed to reveal any significant effects $(p>.05)$. No difference in error rates was observed either. In addition, the faster average RT for "same" responses $(582 \mathrm{msec})$, as compared to the average "different" RT $(609 \mathrm{msec})$, was in agreement with the data of most same-different experiments (cf. Krueger, 1978; Nickerson, 1972, 1978).

Finally, the incidental learning task results demonstrated that the subjects had processed word-noise items to the point of recognition and memory. T tests indicated that the $2 \mathrm{AFC}$ recognition accurary scores for both "same" and "different" words were significantly greater than would be expected by chance alone. The average number of items correctly recognized was $64.4 \%$ and $63.1 \%$ for "same" and "different" noise words, respectively.

\section{EXPERIMENT 2}

The basic notion of unitization is predicted on the assumption that information becomes unitized through recursive integration or strengthening of higher order representations (Hayes-Roth, 1977; Hebb, 1949; Johnson, 1977). Accordingly, an unfamiliar word is difficult to recognize as a unit because its featural package or envelope has not yet been adequately learned; its perception requires attention to its component features (LaBerge, 1975; LaBerge \& Samuels, 1974). A familiar word, on the other hand, likely has an established cogit (Hayes-Roth, 1977) and can therefore be easily identified by its overall configuration, which can be considered the visual analogue of a chunk (Miller, 1956).

The purpose of this experiment was to examine noise-item familiarity effects. In the previous experiment, all the word-noise trigrams were high-frequency (familiar) words that failed to impair RTs for correct "same" responses as much as anagrams. In the present experiment, both familiar and unfamiliar words, as well as their corresponding anagrams, were used as distractors. If familiarity is at least partially responsible for perceptual unitization, unfamiliar words should impair RTs more than familiar words. In fact, unfamiliar words should cause interference effects similar to those caused by anagram noise.
Table 2

Noise Item Used in Experiment 2

\begin{tabular}{|c|c|c|c|c|c|}
\hline \multicolumn{3}{|c|}{$\begin{array}{c}\text { High Familiarity } \\
\text { (Mean Rating }=6.42 \text { ) }\end{array}$} & \multicolumn{3}{|c|}{$\begin{array}{c}\text { Low Familiarity } \\
\text { (Mean Rating }=1.814)\end{array}$} \\
\hline Rating & Word & Anagram & Rating & Word & Anagram \\
\hline 6.51 & Apple & Apepl & 1.67 & Sigit & Sgtii \\
\hline 6.60 & Color & Ooclr & 1.60 & Salol & Aosll \\
\hline 6.47 & Hotel & Htloe & 2.23 & Swage & Saewg \\
\hline 6.23 & Jewel & Eejwl & 1.77 & Anale & Nlaee \\
\hline 6.21 & Lemon & Eolmn & 2.03 & Betel & Btlee \\
\hline 5.92 & Maple & Mpeal & 1.90 & Bhang & Hnbag \\
\hline 6.55 & Money & Oemny & 1.98 & Calix & Clxai \\
\hline 6.25 & Movie & Mveoi & 1.73 & Celom & Eoclm \\
\hline 6.77 & Music & Uimsc & 1.77 & Goral & Grloa \\
\hline 6.16 & Novel & Nvloe & 1.85 & Jupon & Uojpn \\
\hline 6.56 & Sugar & Uasgr & 1.38 & Kulak & Klkua \\
\hline 6.31 & Uncle & Ucenl & 1.85 & Lagan & Aalgn \\
\hline 6.76 & Water & Aewtr & 2.10 & Lapin & Lpnai \\
\hline 6.58 & Woman & Wmnoa & 1.87 & Manus & Aumns \\
\hline 6.20 & Tulip & Uitlp & 1.70 & Menad & Mndea \\
\hline 6.47 & Vodka & Vdaok & 1.59 & Nidus & Iunds \\
\hline 6.37 & River & Iervr & 1.44 & Nisus & Nssiu \\
\hline 6.52 & Penny & Pnyen & 2.07 & Paean & Aapen \\
\hline 6.42 & Light & Ihlgt & 1.70 & Pewit & Pwtei \\
\hline 6.57 & Grass & Gasrs & 2.05 & Rebus & Eurbs \\
\hline
\end{tabular}

Note-Ratings are based on a 7-point scale and data provided by Toglia and Battig (1978).

\section{Method}

Subjects. Six paid volunteers from the University of Illinois served as subjects. All had normal or corrected-to-normal vision.

Stimuli and Apparatus. The target letters were the same as those used in Experiment 1, with the exception that only NI pairs were used for the "same" condition and only the mixed-case pairs were used for "different" pairs. The word-noise items were drawn from a list of $\mathbf{4 0}$ five-letter words chosen on the basis of familiarity ratings provided by Toglia and Battig (1978). On the 7point ascending familiarity scale, the 20 highly familiar words had a mean rating of 6.42 ; the mean rating for the unfamiliar noise words was 1.814. Anagrams were produced by moving the second and fourth letters of each noise word to the initial or end letter positions. Each of the noise items subtended $.85 \mathrm{deg}$ of visual angle in width, making the width of the entire display $1.87 \mathrm{deg}$ of visual angle. The noise items are shown in Table 2.

The apparatus was the same as that used in Experiment 1.

Procedure. Each subject participated in only one experimental session. After receiving the same instructions as given in Experiment 1 , each subject practiced the task by responding to 40 trials. Following these warm-up trials, the subjects viewed 160 experimental displays. These consisted of one random combination of each of the $\mathbf{2 0}$ familiar and 20 unfamiliar words and corresponding anagrams with one of the "different" and one of the "same" target-letter pairs. Each anagram was displayed with the same target pairs as its corresponding word to control for possible extraneous target-noise-item confusions. The eight different target-noise combinations were equally and randomly mixed in blocks of 16 displays each.

\section{Results and Discussion}

In Figure 2, average "same" RTs are plotted as a function of noise type. These data were evaluated in a repeated-measures analysis of variance (Word Familiarity by Word/Anagram). As expected, the effects of familiarity and word/anagram were significant 


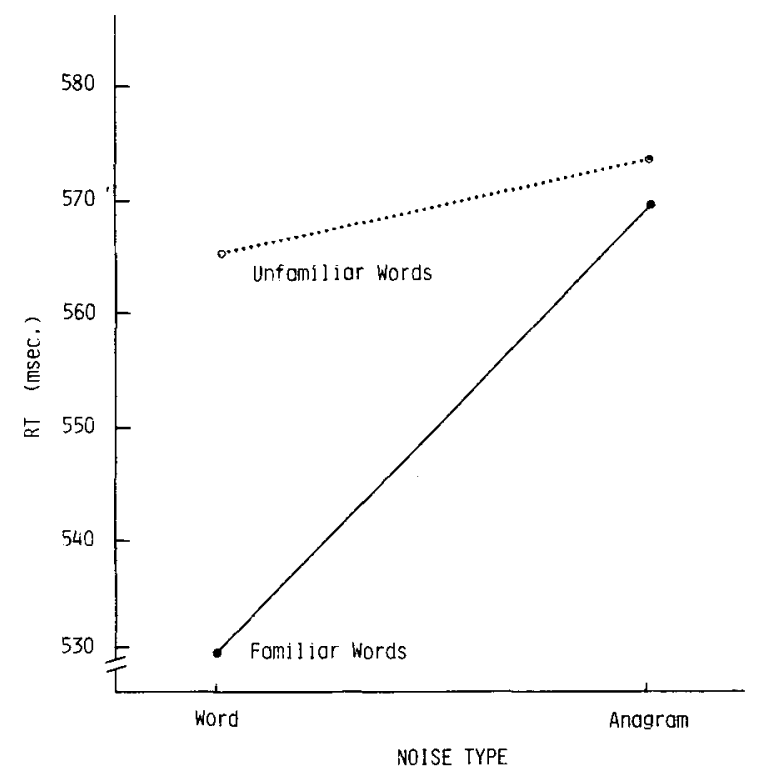

Figure 2. Mean RTs (in milliseconds) as a function of noise type and familiarity.

$[F(1,5)=9.85, p<.05$, and $F(1,5)=16.72, p<.01$, respectively]. The interaction of these factors was also significant $[F(1,5)=7.36, p<.05]$.

As can be seen in Figure 2, the significant interaction is the result of unfamiliar words impairing RTs much more (33 msec) than familiar words. More importantly, unfamiliar words slowed RTs for correct "same" judgments to the same extent as anagram noise items. Average "same" RTs for the unfamiliar words, corresponding anagrams, and familiar word anagrams were 565, 574, and $569 \mathrm{msec}$, respectively. Error rates, again, showed no indication of any speed-accuracy tradeoff. The average error rate for the familiar word-noise condition was $4.1 \%$, and for each of the other three conditions, it was $5 \%$.

These results appear contrary to the data demonstrating that pseudowords are processed more quickly and accurately than unrelated letter strings (Gibson, Pick, Osser, \& Hammond, 1962; Mewhort, 1974; Miller, Bruner, \& Postman, 1954). It is more probable, however, that the present results emphasize the all-or-none assumption of word unitization (HayesRoth, 1977; Johnson, 1977) and the plausibility and usefulness of additional word recognition strategies. Johnson (1977) assumes that the unitization process is involuntary and proceeds in an all-or-none fashion until a response can be made to the entire configuration. If this is not accomplished, the stimulus is parsed according to some other strategy. In a sense, then, rather than being taken as evidence against unitization, the ease with which unfamiliar words or even pseudowords are processed can be taken as evidence for the use of other strategies (i.e., McClelland's preliminary letter analysis) when unitization fails.
Neither the error rates nor the "different" RTs analyzed using a repeated-measures analysis of variance (familiarity by word/anagram) showed any indication of noise effects $(p>.05)$. Also, as before, the average RT for same responses $(560 \mathrm{msec})$ was faster than for different responses $(606 \mathrm{msec})$.

\section{EXPERIMENT 3}

Another variable related to familiarity is meaningfulness, which has received little attention as an influence of supposed unitization effects or word superiority effects because models using this notion are thought to be "inherently paradoxical" (Coltheart, 1972; Henderson, 1974). Meaning is confounded with orthographic regularity. However, this is not always the case (see Henderson, 1974). There are instances where letter strings have minimal orthographic regularity, but still have meaning. The best examples of letter sequences with meaning-orthographic regularity independence are common abbreviations such as FBI or LSD.

This experiment was designed to examine the role that meaningfulness, in the absence of orthographic cues, has upon perceptual unitization. For this purpose, common abbreviations with minimal orthographic regularity, ${ }^{2}$ common words, and anagrams were used as distractors in a classification task similar to that used in Experiment 2. Assuming that common abbreviations are perceptually unitized like familiar words, they should not interfere with the letter comparison task. Anagrams, however, would cause the expected interference effects.

\section{Method}

Subjects. All six of the right-handed paid volunteers were students at the University of Illinois. Each had either normal or corrected-to-normal vision.

Stimuli and Apparatus. The 14 target letters were chosen randomly from the alphabet, excluding, I, Q, O, and Z. The "same" letter pairs were made up of uppercase and lowercase representations of each letter. Seven pairs began and seven ended in capital letters. The "different" letter pairs were made using the same letters as the "same" pairs, with the restrictions that: (1) letter cases be mixed within pairs, (2) an equal number of pairs begin and end with capital letters, and (3) all letters be used equally of ten.

The 14 common words were chosen from Kučera and Francis (1967) in a pseudorandom fashion. They varied in frequency of occurrence from $69,971 / 1,014,232$ for the word THE to $4 / 1,014,232$ for the word TOY.

The 14 three-letter nonacronymous abbreviations made up of initial letters were selected from a larger set based on rated meaningfulness and familiarity. Anagrams were constructed by moving the second letter of each word and abbreviation to either the first or third letter position. Finally, since abbreviations are normally in capital letter form, all the letters of the abbreviations, as well as the common words, were capitalized. The target letters and noise trigrams are displayed in Table 3.

Procedure. The subjects participated in only one experimental 
Table 3

Target Letters and Noise Trigrams Used in Experiment 3

\begin{tabular}{cclll}
\hline $\begin{array}{c}\text { Target } \\
\text { Letter }\end{array}$ & $\begin{array}{c}\text { Abbrevi- } \\
\text { ation }\end{array}$ & $\begin{array}{c}\text { Ana- } \\
\text { gram }\end{array}$ & Word & $\begin{array}{c}\text { Ana- } \\
\text { gram }\end{array}$ \\
\hline M & TWA & WTA & THE & HTE \\
D & CIA & ICA & MAN & MNA \\
E & FBI & BFI & AIR & IAR \\
T & IRS & SRI & CAR & ACR \\
S & DNA & NDA & AND & ADN \\
H & USA & SAU & SKY & KSY \\
A & CBS & CSB & ICE & EIC \\
E & NFL & FNL & TOY & OTY \\
R & LSD & SLD & OIL & IOL \\
K & NBC & BNC & DIG & DGI \\
B & ESP & EPS & OUT & OTU \\
C & UFO & UOF & HER & HRE \\
B & IBM & IMB & HIS & IHS \\
U & RCA & ACR & PEN & EPN \\
\hline
\end{tabular}

session, consisting of two presentations of each of the 140 displays. The latter consisted of the 14 no-noise "same" and 14 "different" letter pairs alone and in combination with the word abbreviation and anagram trigrams. The stimuli were arranged in blocks of 28-two random occurrences of each of the 14 types of displays.

The instructions given the subjects were the same as those used in Experiment 2. Also, as before, the subjects received $\mathbf{4 0}$ warm-up trials, consisting of a set of displays other than those used in the experimental session. Before the experimental trials began, the subjects were told the nature of the irrelevant display items. Finally, after the session was completed, each subject was screened to ensure that the meaningful abbreviations were, indeed, meaningful to him. No subjects failed to recognize any of the abbreviations.

\section{Results and Discussion}

Mean "same" RTs for each subject were subjected to a repeated-measures analysis of variance with trigram type (word, abbreviation) and letter relationship (word/abbreviation, anagram) as factors. The only significant effect was letter relationship $[F(1,5)=$ $11.38, \mathrm{p}<.05$ ]. The anagrams of both familiar words and common abbreviations impaired RTs for "same" name matches much more than their corresponding meaningful forms. These effects are displayed in Figure 3 along with the mean RT for the no-noise condition.

In the case of words, it is plausible that these results reflect the benefits derived from orthographic redundancy. Such an explanation would not, however, adequately account for the abbreviation/anagram effects. Both forms of these trigrams have little orthographic regularity, yet they differentially impaired the letter comparison process.

What, then, are the attributes of the stimuli that are both familiar and meaningful and allow the common words and abbreviations to be perceived differently than their anagrams? Familiarity, in terms of orthographic regularity, is an obvious attribute, but, as noted, it fails to either explain the previous results or by itself imply a processing strategy (Henderson, 1974). Meaningfulness, on the other hand, describes familiar graphemic sequences, but fails to be depen- dent on orthographic structure. Familiarity and meaningfulness seem only to become congruent when referring to particular whole-letter sequences compared to entries in semantic memory (Henderson, 1974, p. 308).

The slight, but nonsignificant, increase in RT caused by words and their anagrams compared to abbreviations and their anagrams is not easily explained; it is due either to chance, as the analysis suggests, or to an abbreviation advantage because of the capitalized letter form-words are not usually fully capitalized. The former explanation is favored, since most of the observed difference is accounted for by the performance of only two of the six subjects.

Contrary to the results of Experiment 1, there was no RT advantage found for the no-noise condition. The mean RT for the no-noise "same" responses was $595 \mathrm{msec}$, while the average RTs for the word-noise and abbreviation-noise "same" responses were 613 and $599 \mathrm{msec}$, respectively. A one-way ANOVA comparing these $\mathrm{RT}$ values indicated no significant difference $(p>.05)$. Examination of the error rates gave no indication of any speed-accuracy tradeoffs (see Table 4).

A repeated-measures analysis of variance similar to that used for "same" RTs indicated no significant effects for any of the noise-type conditions on "different" trials; error rates also showed no difference. Apparently, the more analytical processing used for "different" judgments (Bamber, 1969; Krueger, 1978; Tversky, 1969) enables the subject to somehow override the effects of noise items.

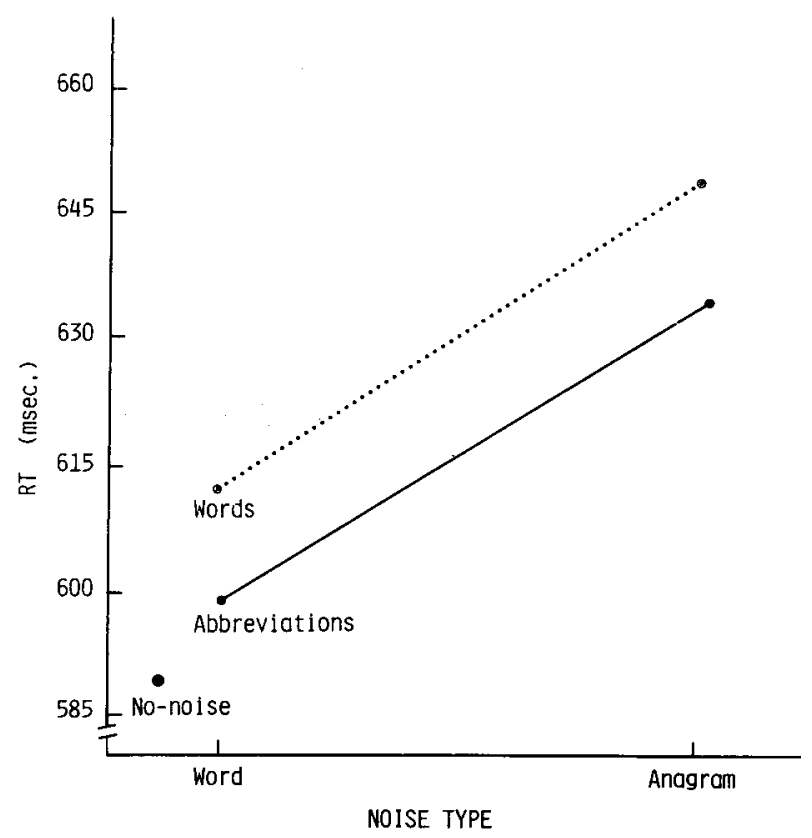

Figure 3. Mean RTs as a function of noise type (word/anagram) and trigram type (word/abbreviation). 
Table 4

Mean "Same" RT (in Milliseconds) and Error Rate (in Percentages) as a Function of Noise Condition in Experiment 3

\begin{tabular}{lcc}
\hline & RT & Error Rate \\
\hline Word & 613.28 & 6.5 \\
Anagram & 647.49 & 9.5 \\
Abbreviation & 599.44 & 7.1 \\
Anagram & 636.63 & 7.7 \\
\hline
\end{tabular}

Finally, the overall RT for correct "different" judgments was slower than for correct "same" judgments-658 compared to $618 \mathrm{msec}$.

\section{EXPERIMENT 4}

One of the experimental results cited to document the pattern-unit model of word recognition is the lack of any length-difficulty relationship for familiar word recognition (Johnson, 1977). Johnson (1975) has, for example, found that the time required to verify whether a word is identical to a predesignated target word is not influenced by letter length, at least within the bounds of from three to eight letters. Based on these results, Johnson hypothesized that the number of features required to recognize perceptually unitized words remains constant regardless of word length.

The issue of length-difficulty relationship is not so easily dismissed, however, because other investigators have found length effects due either to the number of letters (Frederiksen \& Kroll, 1976; McGinnies, Comer, \& Lacey, 1952) or the number of syllables (Eriksen, Pollack, \& Montague, 1970; Spoehr \& Smith, 1973) contained within the words. Although the data indicating a length effect seem damaging for the unitization model, several alternative interpretations and other experimental results diminish their sting. For example, the positive length effects obtained by McGinnies et al. (1952) were found using low-frequency words. These results either disappeared when the subjects became more practiced (Newbigging \& Hay, 1962) or were not even obtained when the stimuli were more familiar (Doggett \& Richards, 1975). It has also been suspected that the factors of syllable length or number affect the preparation of correct responses, not recognition (Eriksen et al., 1970; Klapp, Anderson, \& Berrian, 1973).

The purpose of this experiment was to demonstrate the lack of word-length-difficulty effects when the words are familiar (high frequency). In order to do so, three-, six-, and nine-letter high-frequency words and their anagrams were used as distractors in the same interference task used in Experiments 2 and 3. If perceptual unitization exists, interference effects should not vary as a function of word length.

\section{Method}

Subjects. Six right-handed student volunteers served as paid subjects. Each had normal or corrected-to-normal vision.

Stimuli and Apparatus. The target letter pairs were the same as those used in Experiment 2. However, because the noise items had different lengths, the target letters were displayed vertically-that is, the target letters were displayed in the 12 and 6 o'clock positions of an imaginary clock. The noise sequences were displayed horizontally, directly between the two target letters. The midpoints of the two target letters were separated by $1.74 \mathrm{deg}$ of visual angle, and the noise word was removed from the target letters by $.58 \mathrm{deg}$ of visual angle.

The word-noise items were chosen randomly from Kučera and Francis (1967), with the restriction that none of the words have a frequency of occurrence less than $125 / 1,014,232$. There were 20 examples of three-, six-, and nine-letter-sequence lengths. The number of syllables was not controlled. Anagrams were produced by moving odd-numbered letters from their positions to either the beginning or end of the letter sequence. (See Table 5.)

The apparatus was the same as the one used in the previous experiments.

Procedure. The instructions were similar to those used before. In addition, each subject was forewarned of the type of noise items and instructed to ignore these sequences.

After a 40-trial practice session, each subject was tested in a single session using 280 experimental displays. These consisted of 20 "same" and 20 "different" no-noise trials and 20 single pairings of each of the three length-type words and corresponding anagrams with one of the "same" and "different" letter pairs. The 14 display types were mixed randomly in 20 blocks of 14 displays each.

\section{Results and Discussion}

Average "same" RTs for the word-noise conditions as a function of letter length are plotted in Figure 4. Also included in Figure 4 is the mean RT for the no-noise condition.

As expected, anagram-noise items interfered with the comparison task significantly more than wordnoise items $[F(1,5)=33.98, p<.01]$. A $t$ test also indicated that the average RT for the no-noise trials

Table 5

Noise Words and Anagrams Used in Experiment 4

\begin{tabular}{lll}
\hline Three Letters & \multicolumn{1}{c}{ Six Letters } & \multicolumn{1}{c}{ Nine Letters } \\
\hline Her-Ehr & People-Polepe & President-Peietrsdn \\
Old-Dlo & System-Ytmsse & Different-Dfeetifrn \\
Age-Aeg & Office-Ofcfie & Available-Aalbevial \\
Sat-Ast & Effect-Fetfet & Necessary-Ncsayeesr \\
Try-Rty & Simply-Smlipy & Education-Euaindcto \\
Let-Lte & Record-Eordcr & Attention-Atninteto \\
Few-Efw & Theory-Hoyter & Equipment-Eupetquimn \\
Bad-Abd & Before-Eoebfr & Difficult-Dfiutifcl \\
Son-Osn & Better-Bteetr & Concerned-Cnendocre \\
Aid-Adi & Either-Ihrete & Effective-Efciefetv \\
Law-Alw & Figure-Fgriue & Important-Motniprat \\
Say-Sya & Trying-Rigtyn & Political-Oiiapltcl \\
Cut-Ctu & Member-Mmeebr & Community-Omntcmuiy \\
Low-Olw & Degree-Dgeere & Sometimes-Oeiesmtms \\
Hot-Tho & Little-Ltlite & Secretary-Ertrsceay \\
See-Ese & Matter-Atrmte & Developed-Eeoedvlpd \\
Boy-Oby & Became-Bcmeae & Religious-Eiiurlgos \\
Tax-Atx & Spirit-Prtsii & Statement-Ttmnsaeet \\
Top-Otp & Letter-Lteetr & Direction-Ietodrcin \\
Yes-Sye & Normal-Omlnra & Beautiful-Eatflbuiu \\
\hline
\end{tabular}




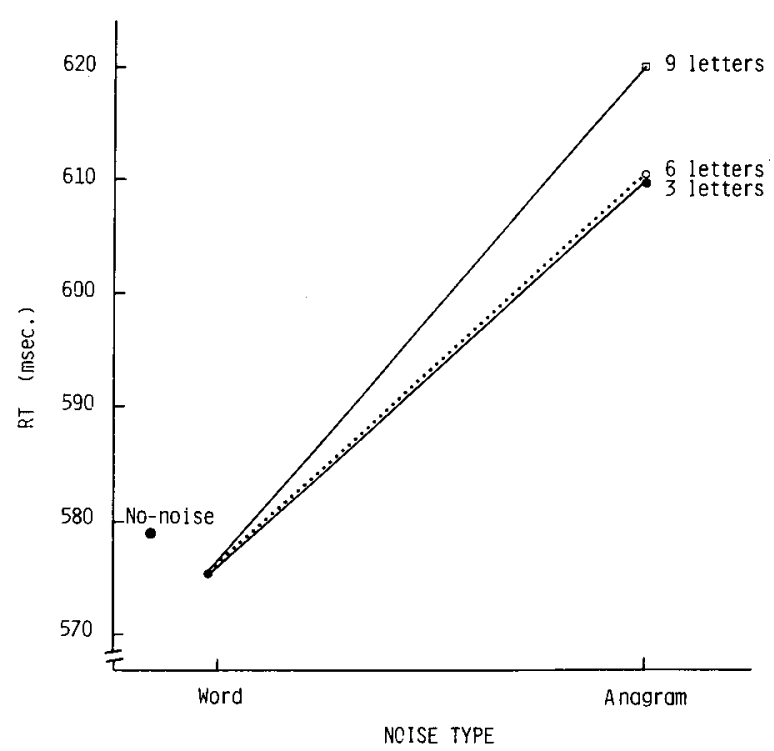

Figure 4. Mean RTs for "same" judgments as a function of noise type (word/anagram) and sequence length. Also included is the average RT for no-noise "same" trials.

was not significantly different from the mean RT for word-noise trials $(p>.05)$. The latter result is consistent with the data from Experiment 3, but not from Experiment 1.

The important finding was that sequence length had no effect for either type of noise condition $[F(2,10)=.18, p>.05]$. In terms of word noise, this result is consistent with a word unitization hypothesis, and supports the notion that the number of features used to recognize unitized words is not a function of word length (Johnson, 1977). In fact, word length may be one of the features enabling words to be unitized (Woodworth, 1938).

One might have assumed that increasing the number of noise letters would have increased the number of target-noise confusions and, therefore, the amount of interference (Eriksen \& Spencer, 1969). On the contrary, when the nature of the comparison task is considered, the lack of anagram length effects is understandable. "Same" judgments are considered holistic (Bamber, 1969; Krueger, 1978). When the process is disturbed either by response-competitive noise items or a mistaken target-letter identification, a more analytical comparison process, like that for "different" judgments, is used. Because this analytical comparison process either allows or waits for the accumulation of added target-letter location and identity information, the interference of distractors is at a minimum. Since there is evidence that the display characters are processed independently (Eriksen, Munsinger, \& Greenspon, 1966) and it only takes one noise item to initiate interference effects (O'Hara, 1977), increasing the number of noise letters should not have a large effect.
The error rates for the word-noise and anagramnoise conditions were equivalent $(5 \%)$, giving no indication of speed-accuracy tradeoffs.

The analysis of average RTs and error rates for "different" responses (Word/Anagram by Word Length) revealed the expected lack of significant effects. Also as expected, the mean RT for "same" responses ( $594 \mathrm{msec}$ ) was faster than for the different responses $(635 \mathrm{msec})$.

Although the results of the present experiment are consistent with the expectations of a perceptual unitization model (Johnson, 1977), there are reasons to be cautious about any strong conclusions. The first of these reasons is the theoretical difficulty associated with the acceptance of the null hypothesis. Rejection of any length-difficulty effects requires such an acceptance.

A second reason for caution concerns the question of the size of the perceptual unit being used. The lack of length effects for words implies only that the word processing did not proceed letter by letter. These results do not exclude the possibility that the words were read by decoding their spelling patterns (Gibson, Pick, Osser, \& Hammond, 1962). Since spelling patterns or letter groups that have invariant relationships with phonemic patterns are also larger than individual letters, they would also not be expected to interfere with the comparison process.

Although the present results do not exclude the possibility that spelling units are the unit of perception, other investigators have pointed out that the spelling pattern approach does have certain difficulties (Spoehr \& Smith, 1973; Adams, Note 1). The most destructive of these is the need to determine the manner in which spelling patterns are parsed together. Unlike words and letters, no single patternmatching strategy will allow for the determination of the particular patterns, because these depend on both surrounding context (e.g., signing vs. signify) or the cluster position within the word.

\section{EXPERIMENT 5}

While discussing the previous results, it was assumed that the interference effects reflected response competition. It was posited that the anagrams and unfamiliar words slowed the comparison of PI and NI target pairs, because their component letters triggered "different" responses (the target and noise letters had different names). Since both "same" and "different" responses could not be made simultaneously, the incorrect "different" response needed to be inhibited before the "same" response could be made. The average time required to establish this inhibition or to release inhibition from the correct response became the observed difference between the mean RTs for the word- and anagram-noise conditions. 
Although the former notion that the effects of noise items are at the response level has received considerable support (Eriksen \& Eriksen, 1974; Eriksen \& Schultz, 1979; Flowers, Warner, \& Polansky, 1979; Keren et al., 1977), there is no consensus in the current literature as to when or how noise items affect the processing of target items. Other attempts to explain the role of noise elements have, for example, located these effects either at perceptual stages of processing (Bjork \& Murray, 1977; Estes, 1974; Regan, 1978) or at a decisional stage (Gardner, 1973; Kinchla, 1974).

One way of evaluating the locus of the noise effects is to make the noise elements tracers. That is, allow the target-noise relationship and the resulting interference effects to signal the locus of the effects. Keren et al. (1977) used this type of design and found that noise elements are processed at least to the same level as target items. In that experiment, subjects made comparison judgments based on the identity of two target letters that surrounded two noise letters. When name-match instructions were given, the results reflected interference effects based on targetnoise name compatibility; however, when categorymatch (vowel-consonant) instructions were given, the subject's RT performance indicated interference based on target-noise category compatibility. Because the interference effects were influenced by the cognitive nature of the noise elements, Keren et al. postulated that the effects could have only been the result of response competition.

In the present experiment, the search for the locus of noise effects was accomplished by using letter homonyms (e.g., b-Bee, C-Sea) as noise items in the standard binary name classification task. This choice of noise items produced target displays with targetletter/homonym-noise matches (e.g., C Sea c) and target-letter/homonym-noise mismatches (e.g., $t$ Why T). Also, for the purpose of comparison, anagrams and nonletter homonym words were used as distractors (e.g., K Tna K and B End b, respectively). If noise items interfere with the processing of target items at a sensory or perceptual level, the cognitive nature of the target-noise items should not influence RTs; RTs for the word-noise conditions should not differ. If, however, the noise effects are the result of response competition, the cognitive relationship between target letters and noise words is very important; "same" RTs for the target-letter/ homonym-noise-matched condition should not differ from those for the word-noise condition. RTs for both of these conditions should, however, be faster than for the target-letter/homonym-noise mismatch conditions. In the latter condition, the word unit can be translated as a letter name that is different from the target letters. Therefore, if this trigram is holistically processed to the point of recognition, it could produce response competition.
Table 6

Target Letters and Noise Trigrams Used in Experiment 5

\begin{tabular}{ccccc}
$\begin{array}{c}\text { Target } \\
\text { Letter }\end{array}$ & $\begin{array}{c}\text { Letter } \\
\text { Homonym }\end{array}$ & $\begin{array}{c}\text { Ana- } \\
\text { gram }\end{array}$ & $\begin{array}{c}\text { Control } \\
\text { Word }\end{array}$ & $\begin{array}{c}\text { Ana- } \\
\text { gram }\end{array}$ \\
\hline B & Bee & Eeb & Bat & Tba \\
C & Sea & Ase & Say & Ysa \\
I & Eye & Eey & End & Dne \\
J & Jay & Jya & Job & Bjo \\
K & Kay & Kya & Kid & Dki \\
P & Pea & Eap & Pot & Tpo \\
R & Are & Era & Ant & Tna \\
T & Tea & Aet & Top & Pto \\
Y & Why & Hwy & Win & Nwi \\
U & You & Oyu & Yes & Sye \\
\hline
\end{tabular}

\section{Method}

Subjects. The eight student subjects were all paid volunteers from the University of Illinois. Each had either normal or correctedto-normal vision.

Stimuli and Apparatus. The letter and display sizes were the same as those used in Experiment 2.

The 10 target letters, from which all target pairs were made, were chosen on the basis of whether a word homonym was available to match them (e.g., B and Bee). The target letters and their corresponding homonyms are listed in Table 6.

The 20 NI target pairs were constructed so that each of the 10 target letters appeared only once in uppercase form in the right and in left pair positions (e.g., B b, b B). The 20 "different" response/different letter case target pairs were constructed using the original set of target letters. First, 10 pairs were made by randomly combining one uppercase and one lowercase representation of each letter so that the first letter of each pair was capitalized. The 10 additional pairs were then made by changing the letter that was capitalized (e.g., B u, b U).

The noise words were of two types. In one set, each of the 10 words was a letter homonym. With the exception of PEA, for which no frequency information was available, each of the words had a frequency of occurrence no less than 11/1,014,232 (Kučera \& Francis, 1967). The 10 words comprising the second set were chosen randomly from Kučera and Francis (1967) with the restriction that the beginning letter of each word match the initial letter of one of the letter homonym words (see Table 6). None of these words had a frequency of occurrence less than $6 / 1,014,232$.

The anagram of each word was constructed by moving the middle letter of each word to the beginning- or end-letter position. In addition, only the first letter of each word or anagram was capitalized.

Procedure. The instructions and use of practice trials were the same as in the previous experiments.

The 20 "same" target pairs and noise-words were combined to produce: (1) 20 target-letter homonym word-noise matches, (2) 20 target-letter homonym word-noise mismatches, and (3) 20 targetletter nonletter homonym word-noise displays. In addition, the 20 "different" target pairs were combined with the noise words to produce: (1) 20 nonletter homonym word-noise displays, and (2) two sets of 20 letter homonym word-noise displays. Anagram noise displays were produced by replacing each of the words in the displays described above with their corresponding anagrams. Including the 20 no-noise "different" and "same" displays, each session consisted of $\mathbf{2 8 0}$ displays pseudorandomly mixed in blocks of 14 displays each.

\section{Results and Discussion}

Analysis of the "different" RTs failed to reveal any significant effects $(p>.05)$.

Response times for "same" judgments as a func- 


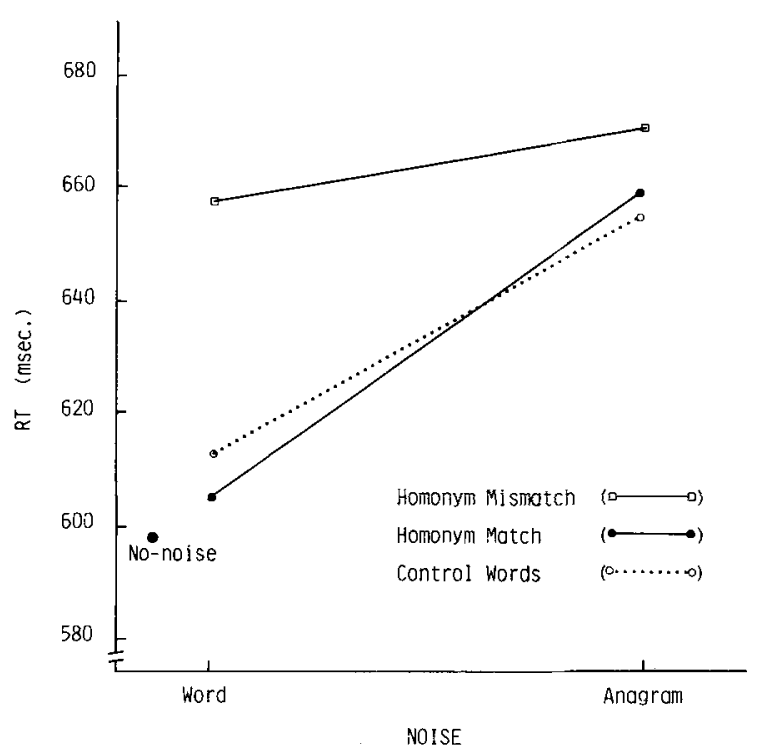

Figure 5. Average RTs for "same" responses as a function of sequence arrangement (word/anagram) and target-noise relationship/ target-letter homonym match (e.g., B Bee b), target-letter homonym mismatch (e.g., $T$ Bee $t$ ), and nonletter homonym control words (e.g., B Pot b). Also shown is the mean RT for no-noise "same" judgments.

tion of target-noise relationship and sequence arrangement (word/anagram) averaged across subjects are presented in Figure 5. Also displayed is the mean RT for the no-noise condition.

At a glance, it can be seen in Figure 5 that the noise effect was very much dependent, as usual, upon the interference effects of anagrams. The repeatedmeasures ANOVA (Sequence Arrangement by TargetNoise Relationship) revealed a significant word/anagram effect $[F(1,7)=13.32, p<.01]$, but no targetnoise relationship effect $(p>.10)$. There was, however, a significant interaction between these two factors $[F(2,14)=8.07, p<.01]$ which, as illustrated in Figure 5, can account for the lack of target-noise relationship effects.

In order to evaluate the effect of target-noise-word relationship effects, a separate one-way ANOVA was used to analyze the "same" word-noise RTs alone. The results indicated a significant effect of targetnoise-word relations $[F(2,14)=8.91, p<.01]$. The shortest RTs were for the target-letter homonyms word-noise match (e.g., T Tea t) and nonletter homonym word (e.g., B Pot b) conditions. When the letter homonym word did not match the target letters (e.g., B Tea b), a large impairment in RT was observed. Post hoc comparisons (Scheffé, 1959) showed that the mean RT for the target-letter homonym word mismatch condition was significantly longer $(p<.05)$ than the mean RT for the target-letter homonym word-noise match condition and the mean
RT for the nonletter homonym word-noise condition. The latter two conditions were not significantly different from each other $(p>.05)$. In addition, a $t$ test gave no indication of a no-noise condition advantage over the nonletter homonym word-noise condition $(p>.05)$. Finally, no indication of speedaccuracy tradeoff effects was observed.

These results are compatible with a response-level explanation of the interference effects. In fact, the differential interference of letter homonym words depending on whether these trigrams were or were not name compatible with the "same" target letters overwhelmingly supports a response competition explanation of the interference effects. Simply described, when considering letter homonym words, the subjects were faster at the name comparison task when the noise word's "intrusive attribute" (its name) was the same as the target letters' "criterial attribute" (their name) and slower when the intrusive and criterial attributes were incongruent (target-letter homonym word-noise mismatch). This interpretation is similar to most explanations of the Stroop effect (Stroop, 1935), in which naming the color of ink in which a word is printed is facilitated or impaired by the cognitive component of the word itself (see Dyer, 1973; Neill, 1978; Proctor, 1978, for reviews).

Finally, the average RT for "same" judgments (637) was faster than for "different" judgments (655).

\section{GENERAL DISCUSSION}

The results of all five experiments yield two basic conclusions: (1) Subjects are not able to completely ignore the irrelevant attributes of an attended display, and (2) under certain conditions, words can be perceptually unitized. It must be emphasized that the subjects' task was the same regardless of the noise type. In a strict sense, therefore, the noise sequences were totally irrelevant to the subjects' task. In addition, there was no uncertainty concerning the position of the targets. Therefore, the observation that $R T$ varied as a function of noise type clearly indicates that subjects cannot solely attend to the target and avoid the processing of noise items-at least with the type of arrangement used in the present experiment.

It is also important to note that the results of all five experiments, particularly those of Experiment 5, indicated that the pronounced interference effects appeared to be at the response level. It was the response compatibility of the noise items and not their presence (except in Experiment 1) that influenced "same" RTs. Moreover, the results of Experiment 5 clearly demonstrated that the influence of the noise items could be manipulated by experimentally defining their response compatibility with the target items. 
Similar effects have been found and similar conclusions have been made by others who used samedifferent tasks (Keren et al., 1977; Krueger, 1973; O'Hara, 1977; O'Hara \& Eriksen, 1979) and letteridentification tasks (Eriksen \& Eriksen, 1974; Eriksen \& Hof fman, 1973; Eriksen \& Schultz, 1979).

The results also reflect a good deal about the actual processing of visual stimuli. That is, the interference effects allow us to trace the flow of visual information processing, revealing the type and degree of processing that elements of the visual display received. For example, the letter homonym interference effects in Experiment 5 suggested that the words were processed to the acoustic naming level, at a rate at least as fast or nearly as fast as the target letters were. If this was not the case, there would have been no RT impairment. In addition, the results suggested that the words were processed differently than the nonwords or the target letters. In fact, the lack of interference at the letter level suggests that the words were perceptually unitized; otherwise, words should have caused RT impairment akin to that produced by anagrams.

The present results also indicate that: (1) the features used to recognize a unitized word need not be the same as those used to identify its component letters, and (2) the letters contained within a unitized word are not, or need not be, recognized prior to the word's recognition. (See Hayes-Roth, 1977, and Johnson, 1977, for reviews.)

The first assumption is merely a theoretical reiteration of the results. It emphasizes the notion that letter-by-letter processing, or any type of wordrecognition process that utilized individual letters, should have produced interference effects. In the absence of such effects, it seems plausible that the words were perceptually unitized using features other than those used for the recognition of letters. Also, it was the meaningfulness and familiarity of the letter sequences that correlated with their interference effects; these attributes refer to the whole sequence, not to the individual components of those sequences. In order to attain any processing benefit from such attributes, the whole-word configuration must be perceptually recognized.

It is not difficult to conceive of word recognition or, for that matter, the recognition of any informationally dense visual stimuli occurring on the basis of the whole integrated configuration. For example, the easy recognition of familiar faces or the enhanced ability of chess masters to reconstruct board descriptions (Chase \& Simon, 1973) suggests that individuals "have memory representations of structure patterns of features" (Hayes-Roth, 1977, p. 265).

Suggesting that the individual letters contained within a unitized word need not be recognized prior to the word's recognition reflects the observation that there was no interference of the letter-matching task when the noise items were familiar whole-letter sequences. Such a notion does not imply, however, that the letters would not be recognized as such, but instead argues that either the whole word is processed faster than the individual letters, or that once recognition responses are made on the basis of the whole word, individual letter identification is either delayed or inhibited. Note that this type of suppression would be both beneficial and adaptive-one notices and overtly responds to parts of something only when the object fails to be recognized as a familiar whole.

In fairness, it needs to be pointed out that the data indicate only that no overt letter recognition responses were made to those noise items that were familiar. The data are not sufficient to preclude the possibility that the letters were recognized at other levels of identification. Accordingly, those favoring preliminary letter models (McClelland, 1977) could argue that the letters in words and nonwords alike activated letter-identification nodes in the perceptual processing system, which, in turn, passed activation along to word-identification nodes. In the case of meaningful noise items, this activation resulted in a recognition response for the unit as a whole. However, when no such response could be made (when the noise items were unfamiliar), overt letter responses were produced. These responses, of course, interfered with the letter-matching task.

Although the latter argument is plausible, it should be noted that the subjects were responding on the basis of letter identity. Therefore, if noise letter clusters interfered (unfamiliar items) or didn't interfere (familiar items), it must be assumed that the recognition response for these items occurred as fast as or faster than the recognition of the two target letters. For this reason, it is more parsimonious to assume that the familiar items were perceived as whole units before their component letters were recognized. Otherwise, one would have to insist that the letters contained within the familiar words activated letter nodes which then activated word nodes, all before the letter-identification nodes corresponding to the target letters were activated.

In keeping with the unitization hypothesis, another explanation of the whole-word benefit over individual letter processing is based on the priority of global over local processing (Kinchla \& Wolfe, 1979; Lupker, 1979). According to this view, the initial visual image is a blur, with only the more gross features being visible. Over time, however, visual information integrates and a more detailed picture of the stimulus - is visible (Eriksen \& Schultz, 1978, 1979). It is quite feasible that perception begins with whatever is available and proceeds from there. Whole-word patterns would therefore get the processing jump on less visibly defined component features and would be more quickly identified if they had learned familiarity. 
Perhaps the most natural conception of a wordprocessing representation suggested by the previous results and discussions is one that combines simple sensory processing with a continuous-flow notion of visual information processing (see Eriksen \& Schultz, 1979). As visual stimulation occurs, a continuous flow of impulses proceeds from the visual receptors to form detectors which, in turn, continuously output information to response systems. The form detectors relay all types of form information, including both global and local features. The response systems could be motor systems, or long-term memory stores which can elicit recognition responses based on the featural information: Note that this conception does not imply that all the information is processed by all the levels of one's memory system, but, instead, that the information is accessible to all levels at the same time. Whether the information is processed or recognized at any level is dependent upon past experiences and learning. For the purpose of word recognition, the long-term memory stores include a graphemic store, a lexical store, and an addressable semantic store. Although each of these stores receives information in a parallel fashion, they also interact in a way to facilitate recognition at each level. Once recognition is achieved at any level, however, the interaction of stores inhibits, or at least biases, decisions at the other levels.

Finally, as the resolution of the initially uncertain visual array proceeds, the number of viable internal recognition responses is reduced, and eventually the threshold for one or a number of responses is made. The noise effects result from the competition produced when the recognition responses produced by irrelevant items are ultimately incompatible with the behavioral or programmed motor responses corresponding to the target letters. This incompatibility requires additional time to resolve and, therefore, an increase in observed RT.

The previous account of perceptual unitization presents a possible summary of what is occurring when an interference paradigm is used. However, just as unitization depends on particular characteristics of the stimulus word, it may also depend upon the experimental paradigm. Although the data from the present experiments are extremely enlightening, the procedures used do lack strong ecological validity. Under more suitable circumstances, a reader is provided with an abundance of contextual information which, no doubt, enhances the efficiency of semantic processing. The present results, therefore, should be considered only a slight indication of the subjects' abilities to perceptually unitize written information. In fact, several investigators have suggested that familiar word sequences might be read in units as large as short phrases or word frames (Drewnowski \& Healy, 1977; Hayes-Roth, 1977).

\section{REFERENCE NOTE}

1. Adams, M. J. Models of word recognition (Tech. Rep. 107). Urbana: Center for the Study of Reading, University of Illinois, October 1978.

\section{REFERENCES}

BAMBER, D. Reaction times and error rates for "same" and "different" judgments of multidimensional stimuli. Perception \& Psychophysics, 1969, 6, 169-174.

Bjork, E. L., \& Murray, J. T. On the nature of input channels in visual processing. Psychological Review, 1977, 84, 472-484.

CAtTell, J. McK. The time taken up by cerebral operations. Mind, 1886, 11, 220-242.

Chase, W. G., \& Simon, H. A. The mind's eye in chess. In W. G. Chase (Ed.), Visual information processing. New York: Academic Press, 1973.

Coltheart, M. Visual information processing. In P. C. Dodwell (Ed.), New horizons in psychology. Hammondsworth, England: Penguin, 1972.

Doggett, D., \& Richards, L. G. A reexamination of the effect of word length on recognition thresholds. American Journal of Psychology, 1975, 88, 585-594.

Drewnowski, A., \& Healy, A. F. Detection errors on the and and: Evidence for reading units larger than the word. Memory \& Cognition, 1977, 5, 636-647.

Dyer, F. N. The Stroop phenomenon and its use in the study of perceptual, cognitive, and response processes. Memory \& Cognition, 1973, 1, 106-120.

Eriksen, B. A., \& Eriksen, C. W. Effects of noise letters upon the identification of a target letter in a nonsearch task. Perception \& Psychophysics, 1974, 16, 143-149.

Eriksen, C. W., \& Hoffman, J. E. The extent of processing of noise elements during selective encoding from visual displays. Perception \& Psychophysics, 1973, 14, 155-160.

Eriksen, C. W., Munsinger, H. L., \& Greenspon, T. S. Identification versus same-different judgment: An interpretation in terms of uncorrelated perceptual error. Journal of Experimental Psychology, 1966, 72, 20-25.

Eriksen, C. W., Pollack, M. D., \& Montague, W. E. Implicit speech: A mechanism in perception encoding? Journal of Experimental Psychology, 1970, 84, 502-507.

Eriksen, C. W., \& Schultz, D. W. Temporal factors in visual information processing. In J. Requin (Ed.), Attention and performance VII. New York: Academic Press, 1978.

Eriksen, C. W., \& Schultz, D. W. Information processing in visual search: A continuous flow conception and experimental results. Perception \& Psychophysics, 1979, 25, 249-263.

Eriksen, C. W., \& Spencer, T. J. Rate of information processing in visual perception: Some results and methodological considerations. Journal of Experimental Psychology, 1969, 79(2, Pt. 2).

Estes, W. K. Redundancy of noise elements and signals in visual detection of letters. Perception \& Psychophysics, 1974, 16, 53-60.

Estes, W. K. The locus of inferential and perceptual processes in letter identification. Journal of Experimental Psychology, $1975,104,122-145$.

Flowers, J. H., Warner, J. L., \& Polansky, M. L. Response and encoding factors in "ignoring" irrelevant information. Memory \& Cognition, 1979, 7, 86-94.

Frederiksen, J. R., \& Kroll, J. F. Spelling and sound: Approaches to the internal lexicon. Journal of Experimental Psychology: Human Perception and Performance, 1976, 2, 361379.

GardneR, G. T. Evidence for independent parallel channels in tachistoscopic perception. Cognitive Psychology, 1973, 4, 130155.

Gibson, E. J., Pick, A., Osser, H., \& Hammond, M. The role of grapheme-phoneme correspondence in the perception of 
words. American Journal of Psychology, 1962, 75, 554-570. Havens, L. L., \& Foote, W. E. The effect of competition on visual duration threshold and its independence of stimulus frequency. Journal of Experimental Psychology, 1963, 65, 6-11.

HAyEs-Roth, B. Evolution of cognitive structures and processes. Psychological Review, 1977, 84, 260-278.

Hев в, D. O. Organization of behavior. New York: Wiley, 1949.

Henderson, L. A word superiority effect without orthographic assistance. Quarterly Journal of Experimental Psychology, 1974, 26, 301-311.

Henderson, L. Do words conceal their component letters? A critique of Johnson (1975) on the visual perception of words. Journal of Verbal Learning and Verbal Behavior, 1975, 14, 648-650.

HUEY, E. B. The psychology and pedagogy of reading. Cambridge: Mass: M.I.T. Press, 1968. (Originally published, 1908.)

JoHnson, N. F. On the function of letters in word identification: Some data and a preliminary model. Journal of Verbal Learning and Verbal Behavior, 1975, 14, 17-29.

Johnson, N. F. A pattern unit model of word identification. In D. LaBerge \& S. J. Samuels (Eds.), Basic processes in reading: Perception and comprehension. Hillsdale, N.J: Erlbaum, 1977.

Kahneman, D. Attention and effort. Englewood Cliffs, N.J: Prentice-Hall, 1973.

Keren, G., O'Hara, W. P., \& Skelton, J. M. Levels of noise processing and attentional control. Journal of Experimental Psychology: Human Perception and Performance, 1977, 3, 653664.

KInChLA, R. A. Detecting target elements in multielement arrays. Perception \& Psychophysics, 1974, 15, 149-158.

Kinchla, R. A., \& Wolfe, J. M. The order of visual processing: "Top-down," "bottom-up," or "middle-out." Perception \& Psychophysics, 1979, 25, 225-231.

Klapp, S. T., Anderson, W. G., \& Berrian, R. W. Implicit speech in reading, reconsidered. Journal of Experimental Psychology, 1973, 100, 368-374.

KRUEGER, L. E. Effects of irrelevant surrounding material on the speed of same-different judgments of two adjacent letters. Journal of Experimental Psychology, 1973, 98, 252-259.

KRUEger, L. E. A theory of perceptual matching. Psychological Review, 1978, 85, 278-304.

Kučera, H., \& Franics, W. N. Computational analysis of present day American English. Providence, R.I: Brown University Press, 1967.

LABERGE, D. Acquisition of automatic processing in perceptual and associative learning. In P. M. A. Rabbitt \& S. Dornic (Eds.), Attention and performance V. London: Academic Press, 1975.

LaBerge, D., \& Samuels, S. J. Toward a theory of automatic information processing in reading. Cognitive Psychology, 1974, 6, 293-323.

LUPKER, S. J. On the nature of perceptual information during letter perception. Perception \& Psychophysics, 1979, 25, 303-312.

Massaro, D. W., Venezky, R. L., \& Taylor, G. A. Orthographic regularity, positional frequency, and visual processing of letter strings. Journal of Experimental Psychology: General, $1979,108,107-124$.

McClelland, J. L. Preliminary letter identification in the perception of words and nonwords. Journal of Experimental Psychology: Human Perception and Performance, 1976, 2, 80-91.

MCClelland, J. L. Letter and configuration information in word identification. Journal of Verbal Learning and Verbal Behavior, 1977, 16, 137-150.

McGinnies, E., Comer, P., \& Lacy, O. L. Visual-recognition thresholds as a function of word length and word frequency. Journal of Experimental Psychology, 1952, 44, 65-69.

Mewhort, D. J. K. Accuracy and order of report in tachistoscopic identification. Canadian Journal of Psychology, 1974, 28, 282-298.
Miller, G. A. The magical number seven plus or minus two: Some limits on our capacity for processing information. Psychological Review, 1956, 63, 81-97.

Miller, G. A., Bruner, J. S., \& Postman, I. Familiarity of letter sequences and tachistoscopic identification. Journal of General Psychology, 1954, 50, 129-139.

NeILL, W. T. Decision processes in selective attention: Response priming in the Stroop color-word task. Perception \& Psychophysics, 1978, 23, 80-84.

Newbigging, P. L., \& HAY, J. The practice effect in recognition threshold determinations as a function of word frequency and length. Canadian Journal of Psychology, 1962, 16, 177-184.

Nickerson, R. S. Binary-classification reaction time: A review of some studies of human information-processing capabilities. Psychonomic Monograph Supplements, 1972, 4(Whole No. 65), 275-318.

Nickerson, R. S. On the time it takes to tell things apart. In J. Requin (Ed.), Attention and performance VII. Hillsdale, N.J: Erlbaum, 1978.

O'HARA, W. P. The spatial and featural effects of irrelevent letters on the speed of same-different judgments of two target letters. Master's thesis, University of Illinois, UrbanaChampaign, 1977

O'HARA, W., \& ERIKSEN, C. W. Word unitization examined using an interference paradigm. Bulletin of the Psychonomic Society, 1979, 14, 81-84.

Posner, M. I., \& Mitchell, R. F. Chronometric analysis of classification. Psychological Review, 1967, 74, 392-409.

Proctor, R. W. Sources of color-word interference in the Stroop color-naming task. Perception \& Psychophysics, 1978, 23, 413-419.

REGAN, J. Involuntary automatic processing in color-naming tasks. Perception \& Psychophysics, 1978, 24, 130-136.

Reiche r, G. M. Perceptual recognition as a function of meaningfulness of stimulus material. Journal of Experimental Psychology, 1969, 81, 274-280.

Scheffé, H. The analysis of variance. New York: Wiley, 1959.

Schultz, D. W., \& Eriksen, C. W. Stimulus size and acuity in visual information processing. Bulletin of the Psychonomic Society, 1978, 12, 397-399.

Sмiтн, F. Understanding reading. New York: Holt, Rinehart \& Winston, 1971

Spoenr, K. T., \& Sмith, E. E. The role of syllables in perceptual processing. Cognitive Psychology, 1973, 5, 71-89.

STroop, J. R. Studies of interference in serial verbal reactions. Journal of Experimental Psychology, 1935, 18, 643-662.

Toglia, M. P., \& Battig, W. Handbook of semantic word norms. Hillsdale, N.J: Erlbaum, 1978.

TVERSKY, B. Pictorial and verbal encoding in a short-term memory task. Perception \& Psychophysics, 1969, 6, 225-233.

WheEler, D. D. Processes in word recognition. Cognitive Psychology, 1970, 1, 59-85.

WoODWORTH, R. S. Experimental psychology. New York: Holt, 1938.

\section{NOTES}

1. The general decrease in RT compared to the results of $O^{\prime}$ Hara and Eriksen (1979) is probably due to the $20 \%$ increase in the size of the letters used in the present experiment (see Schultz \& Eriksen, 1978 , for information about stimulus size and information processing).

2. At present, no satisfactory criteria for orthographic regularity exist (except, see Massaro, Venezky, \& Taylor, 1979). The convention followed here was to consider a letter sequence as irregular if it was either unpronounceable or it consisted of all consonants (e.g., LSD or NBC). Furthermore, a sequence was considered unpronounceable if its graphemic representation was more economical than its phonological representation.

(Received for publication November 1, 1979; revision accepted December $15,1979$. 